\title{
DESAIN LEMBAR KERJA SISWA PADA PEMBELAJARAN STEM UNTUK SISWA SEKOLAH DASAR
}

\section{Ghullam Hamdu ${ }^{1}$, Nur Itsna Rostiana ${ }^{2}$}

Universitas Pendidikan Indonesia, Indonesia

Email: ghullamh2012@upi.edu

\begin{tabular}{|c|c|}
\hline Info Artikel & Abstract \\
\hline $\begin{array}{l}\text { Sejarah Artikel: } \\
\text { Diserahkan } 28 \text { Mei } 2020 \\
\text { Direvisi } 1 \text { November } 2020 \\
\text { Disetujui } 25 \text { November } 2020\end{array}$ & $\begin{array}{l}\text { This study aims to find the right design that can be used by students in achieving } 4 C \\
\text { abilities (communication, collaboration, critical thinking, and creativity). } \\
\text { This research is a Research and Development research with this research stage starting } \\
\text { from needs analysis, drafting design, validation, testing and final revision. This research } \\
\text { was conducted at two different elementary schools in the City of Tasikmalaya. The LKS test } \\
\text { was conducted by describing the changes in the results of the LKS entries by grade } 5\end{array}$ \\
\hline $\begin{array}{l}\text { Keywords: } \\
\text { worksheets, } \\
\text { design, } \\
\text { STEM, } \\
\text { elementary schools }\end{array}$ & $\begin{array}{l}\text { Students in groups at two different elementary schools in the city of Tasikmalaya, West } \\
\text { Java. } \\
\text { The resulting design is a LKS that is based on the STEM learning stages and the revision } \\
\text { LKS is based on the results of student entries in the LKS. The results of this LKS become an } \\
\text { indication of how students can complete assignments by understanding the various } \\
\text { commands or activities contained in the LKS in writing. }\end{array}$ \\
\hline
\end{tabular}

\begin{abstract}
Abstrak
Penelitian ini bertujuan untuk mendapatkan desain yang tepat dan dapat digunakan oleh siswa dalam mencapai kemampuan 4C (communication, collaboration, critical thinking, and creativity).

Penelitian ini merupakan penelitian Research and Development dengan tahap penelitian ini dimulai dari analisis kebutuhan, penyusunan draft desain, validasi, uji coba dan revisi akhir. Penelitian ini dilakukan pada dua sekolah dasar yang berbeda di wilayah Kota Tasikmalaya. Uji coba LKS dilakukan dengan mendeskripsikan perubahan hasil isian dalam LKS oleh siswa kelas 5 secara berkelompok pada dua sekolah dasar yang berbeda di wilayah Kota Tasikmalaya-Jawa Barat.

Desain yang dihasilkan adalah LKS yang berdasarkan tahapan pembelajaran STEM dan revisi LKS didasarkan kepada hasil isian siswa pada LKS. Hasil isian LKS ini menjadi indikasi bagaimana siswa dapat menyelesaikan tugas dengan cara memahami berbagai perintah atau kegiatan yang tertuang dalam LKS secara tertulis.
\end{abstract}

(C) 2020 Universitas Muria Kudus 


\section{Ghullam Hamdu, Nur Itsna Rostiana \\ DESAIN LEMBAR KERJA SISWA PADA PEMBELAJARAN STEM UNTUK ... REFLEKSI EDUKATIKA : Jurnal Ilmiah Kependidikan, Volume 11, Nomor 1, Desember 2020, hlm. 79-87}

\section{PENDAHULUAN}

Hadirnya pembelajaran tematik diharapkan dapat meningkatkan efektivitas siswa dalam belajar sesuai dengan tuntutan kurikulum 2013. Perubahan tuntutan kurikulum ini memiliki dampak yang sangat besar pada implementasi nilai-nilai kehidupan di setiap aspek (Sabri, 2017). Secara lebih khusus, pelaksanaan pembelajaran di sekolah dasar dilakukan dengan memadukan materi ajar pada beberapa mata pelajaran dengan diikat dengan tema (Ananda dan Fadhilaturrahmi, 2018; Kristiantari, 2015). Kurikulum tematik merupakan seperangkat pengalaman belajar terorganisir yang memberikan siswa kesempatan untuk mengeksplorasi secara luas tema pembelajaran utama. Pembahasan materi dengan tema ini menjadi lebih bermakna bagi siswa dengan tidak memunculkan mata pelajaran tertentu secara kontras. Di Lapangan, guru menghadapi hambatan dalam memilih masalah dan tema yang sesuai dalam pembelajaran tematik (Retnawati, et al., 2017).

Pada proses pembelajaran, guru harus memberikan inovasi baru agar siswa mampu mendapatkan pengalaman dalam proses pembelajaran (Blândul, 2015). Inovasi ini diperlukan agar proses pembelajaran menjadi menarik dan menyenangkan. Pembelajaran yang menari dan menyenangkan dapat meningkatkan motivasi belajar siswa (Pratiwi, et al., 2018). Pada pelaksanaan pembelajaran tematik, inovasi yang telah berkembang ditentukan oleh penguasaan terhadap bidang yang saat ini dikenal dengan STEM (Science, Technology, Engineering, and Mathematics). Pendidikan STEM di setiap jenjang pendidikan perlu menjadi perhatian pemerintah sehingga menjadi substansi dan kerangka acuan dalam kurikulum di semua jenjang pendidikan. STEM memungkinkan peserta didik untuk mempelajari konsep akademik secara tepat dengan menerapkan empat disiplin ilmu (Priyani dan Nawawi, 2020). Adanya pendidikan STEM diharapkan terjadinya peningkatan kualitas sumber daya manusia Indonesia agar mampu bersaing dengan lulusan yang masih didominasi oleh lulusan bidang non STEM. Pendidikan STEM sangat relevan dengan pengembangan keterampilan abad 21, yaitu yang dikenal dengan 4C: communication, collaboration, critical thinking, dan creativity (Lestari, et al., 2018; Wulandari, 2019).
Hadirnya pendidikan sains diharapkan dapat menjadi sarana bagi siswa untuk mempelajari diri sendiri dan alam sekitar, serta prospek pengembangan lebih lanjut untuk menerapkan dalam kehidupan sehari-hari. Melalui pembelajaran tematik yang melibatkan proses $4 C$, artinya siswa baik secara individu maupun secara berkelompok dapat mengkonstruk pengetahuan secara otentik. Dalam pembelajaran tematik memberikan pengalaman langsung kapada siswa, guru lebih bertindak sebagai fasilitator yang membimbing siswa untuk mencapai tujuan pembelajaran (Utaminingsih dan Zuliana, 2018). Pendekatan STEM semacam itu memberi kesempatan bagi siswa untuk mengembangkan keterampilan abad ke-21 (Howell, 2015).

Mengacu pada konteks pendidikan dasar STEM, pembelajaran STEM melibatkan pengetahuan dan keterampilan secara bersamaan dalam mencapai kemampuan 4C. Untuk mencapai kemampuan 4C tersebut, diperlukan adanya Lembar Kerja Siswa agar pelaksanaan pembelajaran STEM melibatkan pengetahuan dan keterampilan secara bersamaan dapat mencapai kemampuan $4 C$ pada siswa. Untuk memperoleh produk LKS yang baik perlu maka perlu untuk memperhatikan rambu-rambu sebagai berikut: 1) Pengembangan LKS merupakan gambaran proses tahapan belajar siswa untuk mendapatkan konsep/pengetahuan. 2) Isian siswa dalam LKS sebenarnya tidak bermaksud untuk menilai, namun lebih kepada tahapan belajar yang ditempuh siswa. 3) Setiap isian siswa dalam LKS alangkah baiknya diberi semacam refleksi atau kesimpulan. 4) penulisan kesimpulan tidak harus dituliskan "kesimpulan", namun bermakna pernyataan tersirat (Hamdu dan Sopandi, 2018).

Melalui penggunaan Lembar Kerja Siswa dalam proses pembelajaran, siswa diharapkan dapat mempelajari suatu materi pelajaran secara mandiri (Yaden, 2017). Pedoman pembelajaran yang dikembangkan oleh guru sering disalahartikan sebagai pertanyaan dengan maksud menggali pengetahuan siswa, bukan bagaimana siswa mengalami perolehan pengetahuan. Beberapa siswa dalam proses pembelajaran masih banyak yang belum memahami LKS. Hal itu terlihat dari sikap siswa yang bertanya mengenai isi LKS, bingung dalam mengisi LKS, tidak berani bertanya, dan beberapa bagian LKS dijawab salah oleh siswa. Sehingga, penelitian tentang pengembangan 
LKS tersebut masih perlu dilakukan" (Fatimah, et al., 2019).

Pendidikan STEM dalam konteks pendidikan dasar bertujuan untuk mengembangkan peserta didik yang memiliki literasi STEM (STEM literate) (Bybee, 2013). Pelaksanaan STEM dalam pembelajaran dapat dilakukan dengan tahapan: Ask (Menanya), Imagine (Membayangkan), Plan (Merencanakan), Create (Membuat) dan Improve (Meningkatkan) (Karahan, 2015; Baran, et al., 2016 ). Tahapan STEM tersebut dalam artikel ini dilakukan untuk mencapai kemampuan $4 C$ dalam pelaksanaan pembelajaran.

Tujuan penelitian ini adalah untuk memperoleh desain yang tepat dan dapat digunakan oleh siswa dalam mencapai kemampuan 4C (communication, collaboration, critical thinking, and creativity).

\section{METODE PENELITIAN}

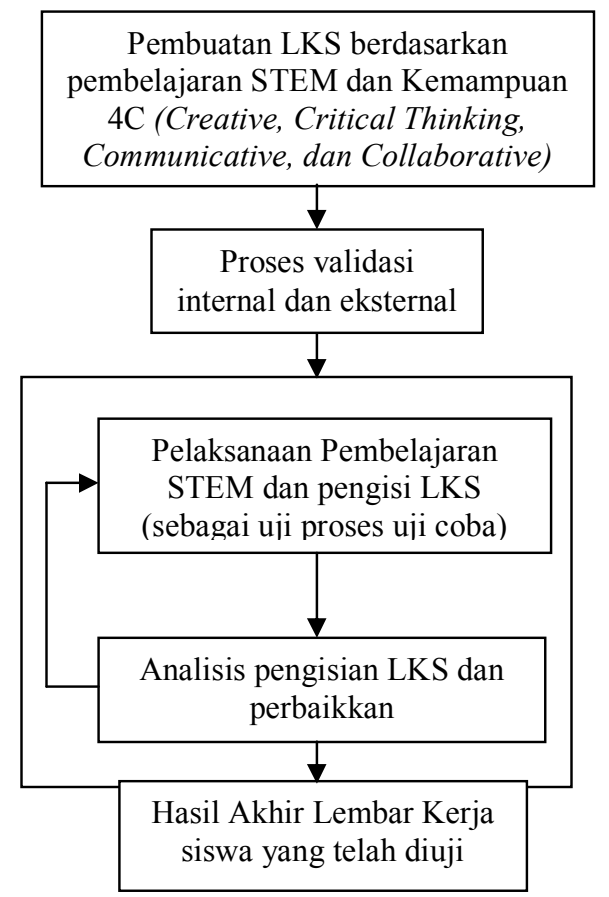

Penelitian ini merupakan penelitian
Research and Development dengan pengembangan LKS yang dilakukan dengan mendeskripsikan perubahan hasil isian dalam LKS. Tahap penelitian ini dimulai dari analisis kebutuhan, penyusunan draft desain, validasi, uji coba dan revisi akhir. Penelitian ini dilakukan pada dua sekolah dasar yang berbeda di wilayah Kota Tasikmalaya. Rancangan LKS yang akan diuji cobakan ini telah divalidasi secara internal dan eksternal. Validasi internal dilakukan dengan cara FGD antara tim peneliti (dosen dan mahasiswa), sedangkan validasi eksternal dilakukan dengan oleh guru SD terpilih dan dosen sejawat.

Teknik pengambilan data menggunakan teknik non tes dengan instrument lebar validasi desain, lembar observasi dan wawancara. Analisis data dilakukan secara deskriptf kuantitatif. Adapun langkah hahapan peroleh data hasil isian LKS oleh siswa dapat dilihat pada Gambar 11 berikut.

Gambar 1. Tahapan peroleh data hasil isian LKS oleh siswa

\section{HASIL DAN PEMBAHASAN}

$\begin{array}{llr}\text { Rancangan } & \text { LKS yang dibuat dalam } \\ \text { penelitian ini } & \text { menggunakan } \\ \text { pembelajaran } & \text { Science, } & \text { Technology, }\end{array}$
Engineering, and Mathematics (STEM) sebagai penerapan pengembangan pembelajaran tematik dalam kurikulum 2013. Adapaun media, alat 
Ghullam Hamdu, Nur Itsna Rostiana

DESAIN LEMBAR KERJA SISWA PADA PEMBELAJARAN STEM UNTUK ...

REFLEKSI EDUKATIKA : Jurnal Ilmiah Kependidikan, Volume 11, Nomor 1, Desember 2020, hlm. 79-87

dan bahan yang digunakan pada saat proses pembelajaran terlihat pada Tabel 1.

Tabel 1. Media, alat dan bahan yang digunakan dalam LKS

\begin{tabular}{|c|c|c|}
\hline No & Bagian LKS & Media, alat, dan bahan yang digunakan \\
\hline 1 & $\begin{array}{c}\text { Aktivitas 1 - Menanya } \\
\text { (Kegiatan menganalisis perbedaan laju mobil) }\end{array}$ & $\begin{array}{c}\text { Alat: } \\
\begin{array}{c}\text { Mobil-mobilan bertenaga otot dan mobil-mobilan bertenaga } \\
\text { batrai. }\end{array}\end{array}$ \\
\hline 2 & $\begin{array}{c}\text { Aktivitas } 2 \text { - Membayangkan } \\
\text { (Kegiatan menganalisis laju mobil bertenaga } \\
\text { pegas) } \\
\end{array}$ & $\begin{array}{c}\text { Media: } \\
\text { Mobil bertenaga pegas }\end{array}$ \\
\hline 3 & $\begin{array}{c}\text { Aktivitas } 3 \text { - Merencanakan } \\
\text { (Membuat rancangan mobil beretnaga pegas) }\end{array}$ & $\begin{array}{c}\text { Media: } \\
\text { Mobil bertenaga pegas }\end{array}$ \\
\hline 4 & $\begin{array}{c}\text { Aktivitas } 4 \text { - Membuat } \\
\text { (Pembuatan produk/Engineering proces) }\end{array}$ & $\begin{array}{l}\text { Alat dan Bahan : } \\
\text { Karpet busa; Seperangkat lem tembak; Cutter; Gunting; Stik } \\
\text { Es krim; Lakban hitam; Klip kertas; Karet; Tusuk sate; Lidi; } \\
\text { Cetakan roda. }\end{array}$ \\
\hline 5 & $\begin{array}{c}\text { Aktivitas } 5 \text { - Meningkatkan } \\
\text { (Membuat lintasan dan bentuk roda baru) }\end{array}$ & $\begin{array}{c}\text { Alat dan bahan: } \\
\text { Meteran; Ontan; Cotton bud; Cutter; Penggaris; Gunting; } \\
\text { Pulpen; Seperangkat lem tembak. }\end{array}$ \\
\hline
\end{tabular}

Syarat penulisan Lembar Kerja Siswa teknis menurut Hamdu dan Sopandi (2018) akan dijadikan rujukan analisis. Selain itu, pengebangan LKS ini didasarkan pada pembelajaran STEM untuk mencapai kemampuan $4 C$ di SD. Adapun matriks pembelajaran berbasis STEM disajikan dalam Gambar

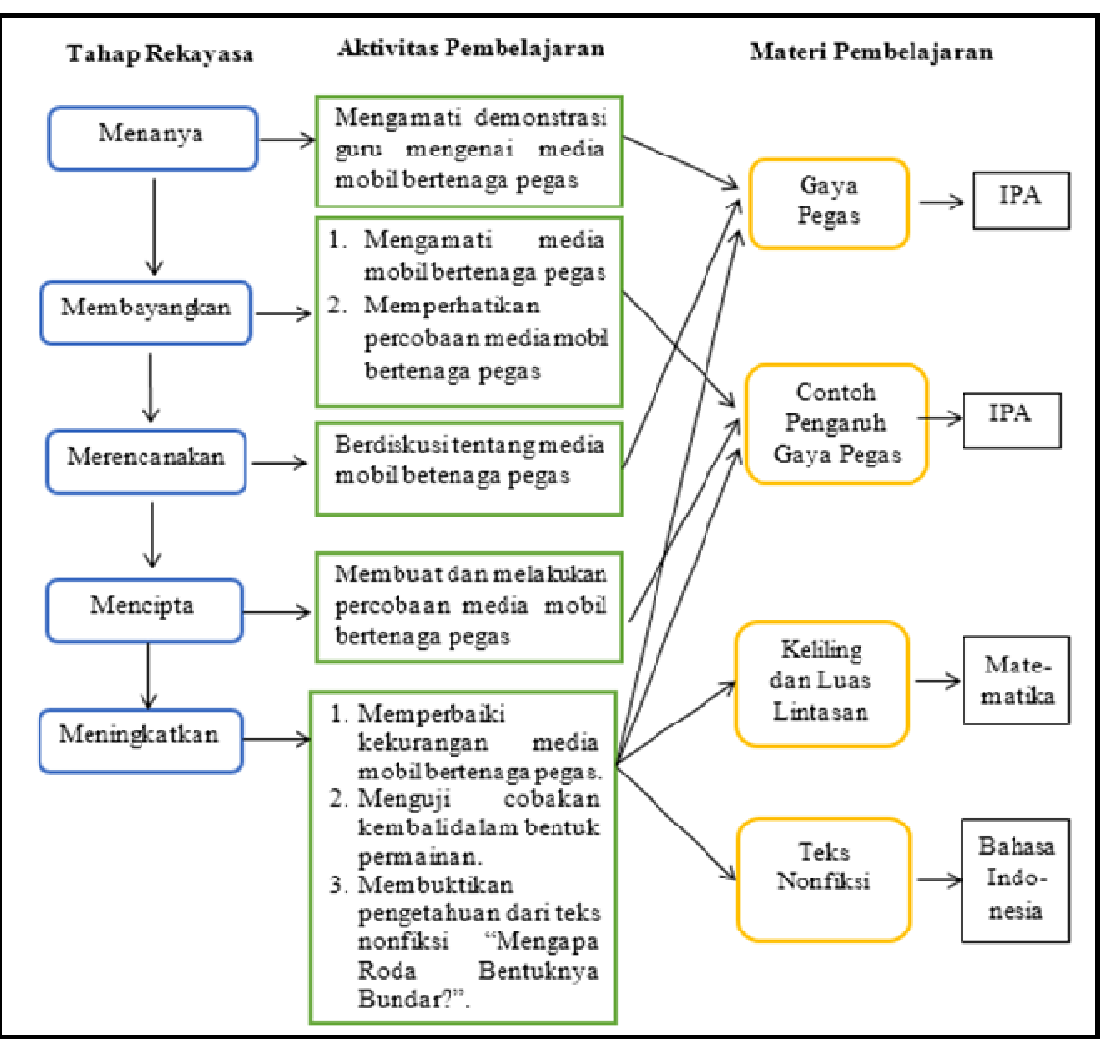

Gambar 2. Matriks Kegiatan Pembelajaran 
Data hasil penelitian ini mendeskripsikan penggunaan LKS dalam pembelajaran. Setelah itu peneliti merevisi LKS berdasarkan pertimbangan dari hasil jawaban kelompok siswa. Isian siswa dari LKS tersebut kemudian dibandingkan dengan jawaban ideal (skor total) yang seharusnya. Kesalahan jawaban siswa ini menjadi refleksi bagi peneliti untuk memperbaiki isi LKS baik secara teknis maupun secara konseptual.

\section{Hasil Uji Coba}

Pelaksanaan pembelajaran STEM untuk uji coba pertama dan kedua dilakukan dengan tahapan yang sama. Tahapan diawali dengan kegiatan pembukaan seperti biasanya, kemudian dilanjutkan dengan kegiatan inti berupa pembagian kelompok. Siswa dibagi menjadi 4 kelompok di uji coba pertama dan 5 kelompok di uji coba kedua. Guru membagikan LKS pada setiap kelompok dan menginstruksikan untuk mengisi identitas kelompok di halaman sampul LKS. Pelaksanaan pembelajaran disesuaikan dengan tahapan pembelajaran STEM yang terdiri dari lima tahapan.

Aktivitas 1 - Menanya (Kegiatan menganalisis perbedaan laju mobil). Pada tahap ini siswa antusias dalam memberikan tanggapan. Selain itu, pada tahap ini kemampuan berpikir kritis siswa sangat terlihat. Dalam pengisian LKS dalam aktivitas ini, terdapat salah satu siswa dari kelompok Bintang Hijau memberikan tanggapan mengenai proses melajunya mobil yang dilakukan oleh guru. Analisis guru terhadap siswa tersebut terlihat dari keraguan siswa terhadap jawaban yang akan dicatat dalam LKS.

Aktivitas 2 - Membayangkan (Kegiatan menganalisis laju mobil bertenaga pegas). Aktivitas diawali dengan demonstrasi guru mengenai mobil bertenaga pegas yang kemudian akan dibuat oleh siswa sebagai produk akhir dari pembelajaran. Sesuai dengan petunjuk dalam LKS, siswa memperhatikan dengan baik terhadap demonstrasi yang dilakukan oleh guru. Guru sedikit memberikan penjelasan mengenai mobil bertenaga pegas serta pengaruh gaya dan gerak dalam kehidupan sehari-hari. Kemudian perwakilan kelompok mencoba untuk mencoba melajukan mobil bertenaga pegas dan diakhiri dengan pengisian LKS sebagai alat untuk menuangkan hasil analisis siswa terhadap masalah yang telah diberikan oleh guru.

Pada tahap ini, siswa tidak ada yang bertanya mengenai alat dan bahan yang harus digambarkan dalam LKS. Akan tetapi, siswa masih ragu-ragu dalam membuat gambar. Hal ini terlihat pada saat pembelajaran bahwa beberapa kelompok ada yang bertanya " $\mathrm{Bu}$, begini bukan gambarnya?". Pada tahap ini, kemampuan $4 C$ satu demi satu mulai terlihat, karena siswa betulbetul memikirkan alat dan bahan apa saja yang dibutuhkan dalam membuat mobil bertenaga pegas. Sehingga proses berpikir kritis dan komunikasi dilakukan oleh siswa.

Aktivitas 3 - Merencanakan (Membuat rancangan mobil beretnaga pegas). Pada tahap ini setiap kelompok berdiskusi mengenai pembuatan mobil bertenaga pegas. Siswa merancang bentuk sasis mobil pada kolom yang disediakan dalam LKS. Penilaian kinerja siswa pada kemampuan $4 C$ mengenai kreativitas kurang terlihat karena terdapat 2 kelompok yang menjiplak bentuk sasis dari mobil bertenaga pegas yang telah disediakan oleh guru, namun ada pula siswa yang bertanya pada guru mengenai rancangan mobil bertenaga pegas sesuai dengan kreativitas kelompok " $\mathrm{Bu}$, boleh bentuk mobilnya begini?".

Aktivitas 4 - Membuat (Pembuatan produk/Engineering proces). Siswa membaca langkah kerja yang terdapat dalam LKS, kemudian setiap kelompok diberi buku panduan mengenai cara pembuat mobil bertenaga pegas. Setelah itu, siswa membaca buku panduan dan mengambil alat dan bahan yang diperlukan oleh masing-masing kelompok. Pada tahap ini, kemampuan siswa dalam berkolaborasi sangat terlihat, semua anggota dalam setiap kelompok bekerja. Diantaranya ada yang mengambil alat dan bahan, ada yang memahami buku panduan hingga pada saat pembuatan mobil bertenaga pegas semua siswa bekerja dalam hal pembuatan roda, menjiplak, menggunting bahkan hingga memasangkan bahan yang diperlukan.

Aktivitas 5 - Meningkatkan (Membuat lintasan dan bentuk roda baru). Siswa diberi kesempatan untuk memperbaiki mobil bertenaga pegas yang telah dibuat. Kemudian setiap kelompok melakukan uji coba dengan membuat lintasan berbentuk bangun datar berdasarkan amplop yang telah dipilih. Pada tahap ini semua siswa ikut berpartisipasi aktif dalam pembelajaran kemampuan $4 C$ sangat terlihat, karena siswa berkolaborasi dalam membuat lintasan berbentuk bangun datar.

Kreativitas siswa dilihat dari hasil lintasan yang telah dibuat. Setiap anggota saling berkomunikasi demi membat sebuah lintasan dan 
Ghullam Hamdu, Nur Itsna Rostiana

DESAIN LEMBAR KERJA SISWA PADA PEMBELAJARAN STEM UNTUK ...

REFLEKSI EDUKATIKA : Jurnal Ilmiah Kependidikan, Volume 11, Nomor 1, Desember 2020, hlm. 79-87

pada akhirnya setiap kelompok menghitung luas dan keliling lintasan yang telah dibuat, disanalah kemampuan berpikir kritis siswa diuji. Dengan kegiatan membuat produk akan meningkatkan kreativitas siswa (Ardianti, et al., 2017). Selain itu, di tahap ini siswa membuat roda mobil dengan bentuk lain (bangun datar sesuai amplop) kemudian melakukan uji coba untuk membuktikan bahwa agar mobil bisa melaju maka roda harus berbentuk bundar. Adapun rekapitulasi hasil analisis jawaban siswa dalam Lembar Kerja Siswa pada pembelajaran STEM uji coba pertama dan kedua terlihat pada Gambar 3 .

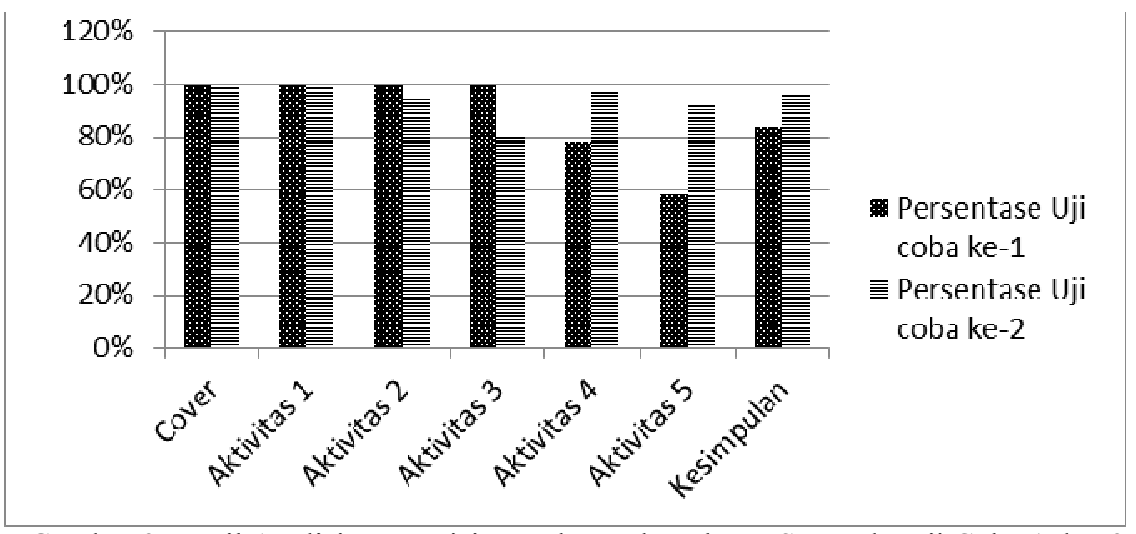

Gambar 3. Hasil Analisis rerata isian Kelompok pada LKS untuk Uji Coba 1 dan 2

Gambar 3 menunjukkan bahwa rerata perolehan pengisian yang benar pada LKS untuk setiap tahapan mengalamai peningkatan. Peningkatan tertinggi pengisian LKS dengan jawaban yang benar terjadi pada aktivitas 5 . Hal ini seluruh siswa aktif melakukan kegiatan sehingga aktivitas siswa meningkat. Senada dengan pendapat, bahwa kegiatan yang dilakukan siswa secara berkelompok dapat memberikan dampak positif terhadap peningkatan aktivitas siswa (Malinda, et al., 2017). Sedangkan penurunan jawaban yang benar terjadi pada aktivitas 2 dan 3. Bentuk peningkatan atau penurunan ini bukan untuk maksud memberikan penilaian terhadap isian siswa. Namun lebih ingin melihat bagaimana siswa memahami pembelajaran STEM dengan LKS dan rekomendasi untuk perubahan LKS, baik secara teknis maupun secara konseptual.

Hasil penelitian juga diketahui bahwa terdapat kesalahan dalam pengisian LKS. Adapu kesalahan kelompok dalam mengisi LKS disajikan pada Tabel 2.

Tabel 2. Kesalahan-kesalahan Jawaban Siswa pada Uji Coba LKS

\begin{tabular}{|c|c|c|}
\hline $\begin{array}{l}\text { Tahap } \\
\text { pembelajaran LKS } \\
\text { yang harus diisi }\end{array}$ & Kesalahan Jawaban Siswa & Jawaban yang diharapkan \\
\hline $\begin{array}{l}\text { Pengisian identitas } \\
\text { (cover) }\end{array}$ & $\begin{array}{l}\text { - Penulisan identitas anggota kelompok yang kurang tepat, } \\
\text { pada kelompok Bintang Orange dikarenakan saat } \\
\text { pembelajaran Rian tidak masuk sekolah. }\end{array}$ & $\begin{array}{l}\text { Penulisan identitas kelompok seharusnya } \\
\text { menuliskan anggota yang hadir pada saat } \\
\text { pembelajaran. }\end{array}$ \\
\hline $\begin{array}{c}\text { Tahap } 2 \\
\text { (Aktivitas } \\
\text { membayangan) }\end{array}$ & $\begin{array}{l}\text { Kelompok Orange nomor } 3 \text { kurang tepat dalam } \\
\text { menjawab petanyaan. Jawaban yang dicatatat tidak sesuai } \\
\text { dengan harapan karena tidak berkenaan dengan hubungan } \\
\text { karet gelang terhadap proses melajunya mobil. Hal ini } \\
\text { dikarenakan siswa dalam kelompoknya kurang } \\
\text { memperhatikan pertanyaan. }\end{array}$ & $\begin{array}{c}\text { Karet gelang sebagai gaya yang } \\
\text { menyebabkan mobil melaju. }\end{array}$ \\
\hline
\end{tabular}


Ghullam Hamdu, Nur Itsna Rostiana

DESAIN LEMBAR KERJA SISWA PADA PEMBELAJARAN STEM UNTUK ...

REFLEKSI EDUKATIKA : Jurnal Ilmiah Kependidikan, Volume 11, Nomor 1, Desember 2020, hlm. 79-87

\begin{tabular}{|c|c|c|}
\hline $\begin{array}{c}\text { Tahap } 3 \\
\text { (Aktivitas } \\
\text { merencanakan) }\end{array}$ & $\begin{array}{l}\text { - Kelompok Orange menggambar rancangan tidak sesuai } \\
\text { dengan perintah yang diberikan oleh guru. }\end{array}$ & $\begin{array}{l}\text { Rancangan gambar yang dibuat seharusya } \\
\text { dibuat berdasarkan bentuk bangun datar } \\
\text { seperti, persegi, persegi panjang, segitiga } \\
\text { sama sisi maupun segitiga kaki. }\end{array}$ \\
\hline $\begin{array}{l}\text { Tahap } 4 \\
\text { (Aktivitas } \\
\text { membuat) }\end{array}$ & $\begin{array}{l}\text { - Pada analisis ke } 2 \text { nomor } 3 \text {, kelompok merah menjawab } \\
\text { "karena diputar karetnya" hal tersebut tidak tepat karena } \\
\text { jawaban tidak sesuai dengan harapan }\end{array}$ & $\begin{array}{c}\text { Karena jumlah putaran karet pada } \\
\text { kerangka mobil A lebih banyak daripada } \\
\text { mobil B, sehingga mobil A melaju lebih } \\
\text { cepat }\end{array}$ \\
\hline
\end{tabular}

Kesalahan kesalahan jawaban siswa tersebut dianalisis kemudian diidentifikasi berbagai penyebab kesalahan tersebut. Hasil analisis kesalahan jawaban siswa ini akan menjadi dasar untuk memperbaiki LKS yang telah dikembangkan. Dalam hal ini, guru dituntut untuk menyelesaikan tugasnya dan perannya tidak lagi sebagai informan ilmu, tetapi perannya harus sebagai motivator dalam proses belajar mengajar sehingga siswa dapat mengkonstruk ilmunya sendiri melalui berbagai kegiatan dalam kegiatan belajar (Yaden, 2017). Melalui penggunaan LKS dalam proses pembelajaran diharapkan siswa dapat mempelajari suatu materi pelajaran secara mandiri (Fhadhila, et al., 2018). Pentingnya LKS ini digunakan untuk belajar secara mandiri maka peneliti menganggap bahwa pengisian dari jawaban siswa sedapat mungkin tidak ada yang salah. Kesalahan siswa menjawab pertanyaan dalam LKS akan menyebabkan siswa mendapatkan konsep yang salah dan memungkinkan siswa tidak dapat memaknai konsep yang telah dipelajari dalam konteks pembelajaran yang telah dilakukan.

Kesalahan-kesalahan tersebut selanjutnya digunakan sebagai bahan perbaikan LKS. Revisi LKS ini dimulai dari kesalahan siswa dalam pengisi hal teknis sampai kepada pencapaian konsep yang diharapkan. Proses belajar dengan LKS menuntun siswa untuk menemukan dan memahami konsep tertentu dengan baik (Choo, et al,. 2011). Proses penananam konsep dilakukan oleh siswa dilakukan dengan mengkonstruk berbagai pengalaman yang dilakukan (Driver, et al., 1994). Perolehan pengalaman belajar yang diperoleh ini dalam konteks pembelajaran di kelas merupakan hasil dari intervensi yang dilakukan guru (Heller, et al., 2012)

Adanya pembelajaran STEM sesuai dengan pelaksanaan kurikulum 2013 yang mengharuskan pembelajaran tematik dan mencapai kemampuan 4C. Pendidikan STEM adalah "pengajaran dan pembelajaran isi dan praktik pengetahuan disipliner yang mencakup sains dan/atau matematika melalui integrasi praktik rekayasa dan perancangan teknik teknologi yang relevan" (Estapa and Tank, 2017). Bersumber pada hasil identifikasi dan analisis masalah serta kurikulum 2013 yang menuntut siswa agar dapat memiliki kemampuan abad 21 yakni kemampuan berpikir kritis, kreativitas, berkomunikasi, dan berkolaborasi atau yang lebih dikenal dengan istilah $4 C$. Maka diperlukan LKS untuk pembelajaran STEM untuk mencapai kemampuan $4 C$ untuk menghasilkan pembelajaran yang bermakna.

Penggunaan Lembar Kerja Siswa sebagai alat untuk melatih siswa berpikir kritis dan menanamkan konsep-konsep yang telah diberikan guru sebelumnya. LKS berisi tuntunan kegiatan bagi siswa dengan cara membangun pengetahuannya tanpa menggantungkan sepenuhnya pada guru. Guru hanya terlibat dalam eksplorasi (memberikan penjelasan teknis) bilamana diperlukan seperti kurang jelasnya pedoman pada LKS atau bila ada pertanyaan yang kurang dipahami oleh siswa. (Hamdu, 2016).

Penggunaan LKS dikatakan sebagai petunjuk langkah kerja dalam belajar di kelas dan membantu siswa dalam menerapkan konsep yang telah dipelajari sebelumnya. "Konsep materi yang ditugaskan dan dibahas di kelas setelah pengenalan lembar kerja, sebagai upaya kelompok. Kemudian siswa diminta untuk menjawab semua pertanyaan pada lembar kerja, tertulis, untuk setiap tugas studi kasus berikutnya". Jawaban-jawaban yang ditulis siswa dalam LKS untuk melihat sejauh mana siswa memahami kosep materi yang telah diberikan, bukan sebagai penilaian pada setiap akhir pembelajaran sehingga guru harus memiliki batas minimal indikator ketercapaian 


\begin{abstract}
Ghullam Hamdu, Nur Itsna Rostiana
DESAIN LEMBAR KERJA SISWA PADA PEMBELAJARAN STEM UNTUK ...

REFLEKSI EDUKATIKA : Jurnal Ilmiah Kependidikan, Volume 11, Nomor 1, Desember 2020, hlm. 79-87
\end{abstract}

pemahaman konsep materi yang sedang dipelajari dalam LKS (Bmns, 2015). LKS sebagai pedoman belajar siswa harus dikembangkan oleh guru secara baik.

\section{SIMPULAN}

Pencapaian pembelajaran berbasis STEM dengan menggunakan LKS dapat membantu guru untuk mengidentifikasi kemampuan 4C siswa melalui aktivitas pembelajaran: menanya, membayangkan, merencanakan, membuat dan meningkatkan. Sejumlah aktivitas belajar tersebut dilalui oleh siswa dan erat kaitannya dengan proses bagaimana siswa memperoleh sejumlah pengetahuan. LKS dapat digunakan oleh siswa untuk mendapatkan pengetahuan melalui sejumlah proses dan kegiatan yang terencana oleh guru. Pengembangan LKS untuk kepentingan belajar siswa bukan bermaksud untuk menguji siswa. Oleh sebab itu, kepentingan LKS lebih kepada proses belajar siswa sehingga dapat memperoleh pengetahuan yang benar. Pengujian keterpakaian LKS perlu melihat dari perspeksif siswa, dalam artian seorang guru perlu menganalisis bagaimana siswa menyelesaikan tugas dengan cara memahami berbagai perintah atau kegiatan yang tertuang dalam LKS.

\section{DAFTAR PUSTAKA}

Ananda, R., dan Fadhilaturrahmi, F. 2018. Analisis Kemampuan Guru Sekolah Dasar dalam Implementasi Pembelajaran Tematik di SD. Jurnal Basicedu, 2(2): 1121.

Ardianti S.D., Pratiwi I.A., dan Kanzunnudin, Moh. 2017. Implementasi Project Based Learning Berpendekatan Science Edutainment Terhadap Kreativitas Peserta Didik. REFLEKSI EDUKATIKA : Jurnal Ilmiah Kependidikan, 7 (2): 145-150.

Baran, E., Bilici, S. C., Mesutoglu, C., and Ocak, C. 2016. Moving STEM beyond schools: Students' perceptions about an out-ofschool STEM education program. International Journal of Education in Mathematics Science and Technology, 4 (1): 9-19.

Blândul, V. C. 2015. Inovation In EducationFundamental Request Of Knowledge
Society. Procedia-Social and Behavioral Sciences, 180 :484-488.

Bmns, H. 2015. Worksheet for Ethics Instruction and Exercises in Reason.

Bybee, R. W. 2013. The Case for STEM Education: Challenge and Opportunities. National Science Teachers Association.

Choo, S. S., Rotgans, J. I., Yew, E. H., and Schmidt, H. G. 2011. Effect Of Worksheet Scaffolds On Student Learning In Problem-based Learning. Advances In Health Sciences Education, 16 (4): 517.

Driver, R., Asoko, H., Leach, J., Scott, P., and Mortimer, E. 1994. Constructing Scientific Knowledge In The Classroom. Educational researcher, 23 (7): 5-12.

Estapa, A, T and Tank, K, M. 2017. Supporting Integrated STEM In The Elementary Classroom: A Professional Development Approach Centered On An Engineering Design Challenge. International Journal of STEM Education, 4, (6): 1-16.

Fhadhila, F., Ertikanto, C., and Rosidin, U. 2018. Developing Student Worksheet Of Temperature And Heat Based On Scientific Process Skill. Jurnal Ilmiah Pendidikan Fisika Al-BiRuNi, 7 (1).

Fatimah, S., Hamdu, G., dan Nugraha, A. 2019. Pengembangan Lembar Kerja Siswa pada Pembelajaran Outdoor Berbasis STEM di Sekolah Dasar. Pedadidaktika: Jurnal Ilmiah Pendidikan Guru Sekolah Dasar, 6 (1): 101-107.

Hamdu, G. 2016. Perangkat Pembelajaran Berbasis Masalah Secara Tematik di Sekolah Dasar. Bandung: Pelangi Press.

Hamdu, G., dan Sopandi, W. 2018. Debriefing Program for Prospective Elementary School Teachers in Developing Learning Aids. International Journal of Learning, Teaching and Educational Research, 17(6). 
Ghullam Hamdu, Nur Itsna Rostiana

DESAIN LEMBAR KERJA SISWA PADA PEMBELAJARAN STEM UNTUK ...

REFLEKSI EDUKATIKA : Jurnal Ilmiah Kependidikan, Volume 11, Nomor 1, Desember 2020, hlm. 79-87

Heller, J. I., Daehler, K. R., Wong, N., Shinohara, M., adn Miratrix, L. W. 2012. Differential Effects Of Three Professional Development Models On Teacher Knowledge And Student Achievement In Elementary Science. Journal of research in science teaching, 49 (3): 333-362.

Howell, J. 2015. A STEM Narrative: 15 Years in the Making. Australian Journal of Teacher Education, 40, (7): 102-112.

Karahan, E., BİLİCI, S. C., and Ünal, A. 2015. Integration Of Media Design Processes In Science, Technology, Engineering, And Mathematics

(STEM) Education. Eurasian Journal of Educational Research, 15(60): 221-240.

Kristiantari, M. R. 2015. Analisis Kesiapan Guru Sekolah Dasar Dalam Mengimplementasikan Pembelajaran Tematik Integratif Menyongsong Kurikulum 2013. JPI (Jurnal Pendidikan Indonesia), 3 (2).

Lestari, D. A. B., Astuti, B., dan Darsono, T. 2018. Implementasi LKS Dengan Pendekatan STEM (Science, Technology, Engineering, And Mathematics) Untuk Meningkatkan Kemampuan Berpikir Kritis Siswa. Jurnal Pendidikan Fisika dan Teknologi, 4 (2): 202-207.

Malinda Z.A., Murtono, dan Zuliana E. 2017. Problem Based Learning Berbantuan Lego Meningkatkan Pemecahan Masalah Siswa Sekolah Dasar. REFLEKSI EDUKATIKA : Jurnal Ilmiah Kependidikan, 8 (1): 66-73.

Murtikusuma, R. P. 2017. Pengembangan Lembar Kerja Siswa Matematika Model Problem-Based Learning Untuk SMK Perkebunan Bertemakan Kopi Dan Kakao. Pancaran Pendidikan, 5 (4): 5160 .
Pratiwi I.A., Ardianti S.D., dan Kanzunnudin, Moh. 2018. Peningkatan Kemampuan Kerjasama Melalui Model Project Based Learning (PjBL) Berbantuan Metode Edutainment Pada Mata Pelajaran Ilmu Pengetahuan Sosial. REFLEKSI EDUKATIKA : Jurnal Ilmiah Kependidikan, 8(2): 177-182.

Priyani N.E., dan Nawawi. 2020. Pembelajaran IPA Berbasis Ethno-STEM Berbantu Mikroskop Digital Untuk Meningkatkan Keterampilan Proses Sains Di Sekolah Perbatasan. WASIS: Jurnal Ilmiah Pendidikan, 1 (2): 99-104.

Rahayu, A., Muhsetyo, G., dan Rahardjo, S. 2016. Pengembangan LKS Bercirikan Problem Based Learning untuk Siswa SMP Ar-rohmah Malang Kelas VII. Jurnal Pendidikan: Teori, Penelitian, dan Pengembangan, 1 (6): 1056-1066.

Retnawati, H., Munadi, S., Arlinwibowo, J., Wulandari, N. F., dan Sulistyaningsih, E. 2017. Teachers' Difficulties In Implementing Thematic Teaching And Learning In Elementary Schools. The New Educational Review, 48: 201-212.

Sabri, T. 2017. Value Based Thematics Learning. Journal Of Education, Teaching and Learning, 2 (2): 192-196.

Utaminingsih, S., dan Zuliana., Eka. 2018. Design of Thematic Integrative Learning Based on Local Advantage in Elementary School. REFLEKSI EDUKATIKA : Jurnal Ilmiah Kependidikan, 9 (1): 75-81.

Wulandari, D. 2019. Penerapan Model Pembelajaran Inkuiri Terbimbing Menggunakan STEM Untuk Meningkatkan Keterampilan Berfikir Kreatif Pada Materi Pemanasan Global. Inovasi Pendidikan Fisika, 8 (3).

Yaden, Z. 2017. A Development of Students' Worksheet Based on Contextual Teaching and Learning. International Journal of Learning, Teaching and Educational Research, 16 (6). 